\title{
Characterization of a $\mathrm{BHK}\left(\mathrm{TK}^{-}\right)$Cell Clone Resistant to Postattachment Entry by Herpes Simplex Virus Types 1 and 2
}

\author{
RICHARD J. ROLLER ${ }^{1 *}$ AND BETSY C. HEROLD ${ }^{2}$ \\ Department of Microbiology, University of Iowa, Iowa City, Iowa 52242, ${ }^{1}$ and Section of \\ Pediatric Infectious Diseases, The University of Chicago, Chicago, Illinois $60637^{2}$
}

Received 6 March 1997/Accepted 2 May 1997

\begin{abstract}
BHK $\left(\mathrm{TK}^{-}\right)$cells selected for resistance to polyethylene glycol-mediated fusion give rise to clones that are resistant to herpes simplex virus (HSV) infection. We have characterized one such clone, designated 95-19, and found that it is resistant to entry of HSV type 1 (HSV-1), HSV-2, and the related alphaherpesvirus pseudorabies virus (PRV). Single-step growth experiments show no detectable replication of multiple strains of HSV-1 and HSV-2 on 95-19 cells. Three lines of evidence suggest that these cells are resistant to postattachment entry. (i) Measurements of binding of radiolabeled virus show that heparin-sensitive binding of HSV-1 and HSV-2 to 95-19 cells is identical to binding to $\mathrm{BHK}\left(\mathrm{TK}^{-}\right)$cells, suggesting that the block to replication occurs after attachment to heparan sulfate proteoglycan. (ii) 95-19 cells exposed to HSV-1 or HSV-2 at high multiplicity show no detectable immediate-early (IE) mRNA expression. (iii) Exposure of attached virus and cells to polyethylene glycol results in partial recovery of both IE gene expression and virus yield in single-step growth. The degrees of recovery of single-step yield and IE gene expression are similar, suggesting that the only block to single-step replication is at the point of virus entry and that these cells are deficient in some cellular factor required for efficient postattachment entry of free virus. 95-19 cells are also highly resistant to entry by cell-to-cell spread, suggesting that the same cellular factor participates in both types of entry.
\end{abstract}

The entry of herpes simplex virus (HSV) into host cells occurs by fusion of the viral envelope with the cellular plasma membrane $(14,43)$. Besides the membranes themselves, this process requires the participation of viral and cellular factors that mediate recognition of the cell by the virus and execute the fusion event. The viral glycoproteins that are absolutely required for efficient penetration have been identified, and a critical role for cell surface proteoglycan in attachment has been demonstrated, but the number and types of virus-cell interactions that mediate entry have not been fully defined.

HSV entry is presumably a complex multistep process. For most cell types studied, the initial step is a low-affinity attachment to the cell surface mediated by an interaction between cell surface heparan sulfate proteoglycan and either or both of the virion glycoproteins $\mathrm{gB}$ and $\mathrm{gC}(17,18,38,44)$. Following this initial low-affinity attachment, there may be secondary, higher-affinity binding events that lead to viral fusion. Fusion of the virus envelope with the cell surface absolutely requires at least four virion glycoproteins $(\mathrm{gB}, \mathrm{gD}, \mathrm{gH}$, and $\mathrm{gL})$ and unidentified cellular factors $(5,11-14,19,20,26,27,35,36)$.

Beyond its role in mediating attachment, Shieh and Spear (39) have presented evidence that the binding of heparan sulfate may be required for the subsequent membrane fusion event, since cell-cell fusion induced by HSV is inhibited in cells that do not express heparan sulfate but can be enhanced in such cells if soluble heparin is provided. HSV can, however, enter mutant cells that fail to express heparan sulfate, albeit inefficiently, and can furthermore enter MDCK cells via the basolateral surface $(15,37)$. These cells express no heparan sulfate at the basolateral surface, and virus particles that do not carry $\mathrm{gC}$ enter by this route as efficiently as particles that do

\footnotetext{
* Corresponding author. Mailing address: Department of Microbiology, The University of Iowa, 3-752 Bowen Science Bldg., Iowa City, IA 52242. Phone: (319) 335-9958. Fax: (319) 335-9006.
}

carry gC (37). There may therefore be alternate attachment receptors, although the virion factor(s) that interacts with these receptors has not yet been identified.

There is strong evidence that, following initial attachment mediated by $\mathrm{gC}$ and/or gB, HSV virions must undergo a second interaction with the cell surface, mediated by the viral gD. Functional $\mathrm{gD}$ is essential for entry, since $\mathrm{gD}$-negative virions and virions treated with anti-gD neutralizing antibodies fail to enter cells. Their failure may be overcome by exposure of cells and attached virus to polyethylene glycol (PEG), which nonspecifically promotes membrane fusion $(12,14,19,26)$. gD mediates infection at least in part by binding to a cell surface receptor, as shown by the ability of UV-irradiated, gD-bearing virions or soluble $\mathrm{gD}$ to block infection by subsequently added virus in a saturable manner $(22,23)$. The cellular gD-binding receptor has not yet been identified. Brunetti et al. showed that a small fraction of the membrane-associated form of $\mathrm{gD}$ found in infected cells is modified with mannose-6-phosphate and that $\mathrm{gD}$ can bind to mannose-6-phosphate receptors (4). These authors subsequently showed that antibodies directed against the mannose-6-phosphate receptor and a soluble form of the receptor block infection only to a small degree (3). The significance of this interaction in normal infection is unclear.

The entry of free HSV virions into a host cell may occur by a different mechanism from that used for cell-to-cell spread. It has been shown for both HSV type 1 (HSV-1) and the closely related pseudorabies virus (PRV) that $\mathrm{gD}$ (or its PRV homolog, gp50) is essential for the entry of free virus into host cells, since virus particles that do not carry these proteins fail to initiate infection $(26,31,33)$. If, however, the entry of gp50PRV could be effected with PEG, the virus could infect adjacent cells to form plaques, suggesting that gp50 is not essential for cell-to-cell spread. The closely related human alphaherpesvirus varicella-zoster virus (VZV) has no homolog of HSV-1 $\mathrm{gD}$ and spreads exclusively by cell-to-cell infection. Although 
HSV $\mathrm{gD}$ is essential for efficient cell-to-cell spread, it is not certain that it plays the same role as in entry of free virus. In both HSV and PRV, the gE and gI proteins are required for efficient cell-to-cell spread but not for entry of free virus $(1,9$, $10,24,30)$. It thus seems clear that the viral and cellular factors required for cell-to-cell spread are at least somewhat different from those required for infection by free virus. There is as yet very little information available about the cellular factors necessary for cell-to-cell spread. Cell surface heparan sulfate may be dispensable for cell-to-cell spread, since Gruenheid et al. observed that the impairment of plaque formation in heparan sulfate-deficient L cells was no greater than the impairment in binding of free virions and that the plaques formed were indistinguishable from those formed on normal L cells (15).

HSV-1 and HSV-2 are closely related viruses and are assumed to enter cells by very similar mechanisms. Recent evidence, however, suggests that some viral glycoproteins may play different roles in these two viruses and that the cellular factors involved in entry may be different. Such differences may contribute to known differences in epidemiology and cell and tissue tropism. Although heparan sulfate serves as a receptor for the attachment of both HSV-1 and HSV-2, the specific features of heparan sulfate recognized are different for each serotype, and the relative contributions of envelope glycoproteins to viral binding are different (16). HSV-1 and HSV-2 may also require distinct cellular factors for postattachment stages of entry. Shieh et al. (38) have shown that wild-type CHO cells support normal heparin-sensitive attachment of both HSV-1 and HSV-2 and are highly resistant to entry by some strains of HSV-1 but less resistant to HSV-2 infection. This suggests that HSV-2 can use postattachment receptors that some strains of HSV-1 cannot.

One powerful tool for the identification of critical interactions between virus and host cell involves the use of host cell lines that do not support efficient infection. Such lines must fail to support at least one essential interaction and may provide a direct approach to the identification of the viral and cellular factors that interact. Several cell lines that are resistant to HSV entry at postattachment steps have been described. Several groups have isolated lines that express gD from HSV-1 or HSV-2 and are resistant to HSV infection $(6,23)$. These cells have been used for the selection of escape mutants of HSV-1 that can grow more efficiently than wild-type, and which map in the $\mathrm{gD}$ gene, suggesting that these cells fail to support an essential interaction between the cell surface and $\mathrm{gD}(2,6-8)$. A BHK-derived cell line that expresses the HSV-1 U 11 protein has also been shown to be resistant to gD-mediated postattachment entry (34). Two other cell lines that are resistant to attachment at a postattachment step but express no viral genes have been described. Wild-type $\mathrm{CHO}$ cells and swine testis (ST) cells allow efficient heparin-sensitive attachment but are resistant to HSV entry $(38,42)$. $\mathrm{CHO}$ cells have been used to select a cDNA, which encodes a previously unidentified member of the nerve growth factor and tumor necrosis factor alpha receptor family called herpesvirus entry mediator (HVEM), that can enhance the susceptibility of both of these cell types to infection by a variety of HSV strains (29). HVEM fails to enhance susceptibility to several viruses carrying substitution mutations in the gene encoding gD, suggesting that HVEM and $\mathrm{gD}$ functionally interact in HVEM-mediated entry. Neither CHO nor ST cells combine the qualities of (i) high-level, stable resistance to both HSV-1 and HSV-2, suitable for genetic identification of cellular entry factors required for entry of both types; (ii) resistance only to entry, allowing the selection of virus escape mutants; and (iii) derivation from a highly susceptible parent cell line that can be used as a standard of comparison and positive control.

$\mathrm{BHK}\left(\mathrm{TK}^{-}\right)$cells are susceptible to HSVs and have been used for the isolation and propagation of recombinant viruses. It has previously been reported that $\mathrm{BHK}\left(\mathrm{TK}^{-}\right)$cells spontaneously give rise to cells that are highly resistant to infection by HSV-1 and that these cells may be somewhat enriched by selection for resistance to death by PEG-induced fusion (34). The resistance to infection reported in that study manifested itself as a failure to support efficient plaque formation. Plaque formation is a relatively complex process that requires entry of the infecting virus into the cells, replication within the infected cell, and spread of the replicated virus from cell to cell. The step at which plaque formation was blocked in these spontaneously resistant clones was left undetermined.

We report here that one of these spontaneously resistant clones, called $95-19$, is highly resistant to infection by HSV-1 and HSV-2 and that this resistance is mediated at a step following attachment of the virus to cell surface proteoglycan but prior to fusion of the virus and cellular membranes. The only block to single-step viral replication in these cells occurs at entry, making them a highly attractive system for the study of virus-cell interactions in postattachment HSV entry.

\section{MATERIALS AND METHODS}

Cells and viruses. $\mathrm{BHK}\left(\mathrm{TK}^{-}\right)$and $95-19$ cells were maintained in Dulbecco's modified Eagle's medium (high glucose) supplemented with 5\% fetal bovine serum. Vero cells were maintained in Dulbecco's modified Eagle's medium (high glucose) supplemented with 5\% newborn calf serum. The wild-type viral strains used were the Indiana strain of vesicular stomatitis virus (VSV), the Kaplan strain of PRV, HSV-1(F), HSV-1(KOS), HSV-2(G), and HSV-2(333). Mutant HSV-1 strains R5000, U21 (a gift of G. Campadelli-Fiume), and rid-1 and rid-2 (a gift of P. G. Spear) have been previously described (2, 8, 34). The recombinant HSV-1(17)(dUTPase/LAT) contains the Escherichia coli $\beta$-galactosidase gene under the control of the viral dUTPase promoter in place of both copies of the LAT genes and has been described previously (a gift of Ed Wagner, University of California, Irvine, Calif.) (40).

Measurement of virus replication in single-step growth. Cultures of $\mathrm{BH}$ $\mathrm{K}\left(\mathrm{TK}^{-}\right)$and $95-19$ cells were exposed to virus at a multiplicity of infection of 10 for $90 \mathrm{~min}$ at $4^{\circ} \mathrm{C}$ to allow the attachment of virus. The inoculum was then aspirated, and the cells were washed three times in warm phosphate-buffered saline (PBS) and placed at $37^{\circ} \mathrm{C}$ in growth medium. This was designated time zero of infection. After incubation for $90 \mathrm{~min}$ to allow virus entry and initiation of infection, the cells were washed once rapidly with citrate buffer $(50 \mathrm{mM}$ sodium citrate plus $4 \mathrm{mM} \mathrm{KCl}$, adjusted to $\mathrm{pH} 3.0$ with $\mathrm{HCl}$ ) and then incubated in a second wash of citrate buffer for $1 \mathrm{~min}$ to inactivate most of the residual virus. The monolayers were then washed twice in PBS and incubated in growth medium for the remainder of the infection. At various times, cultures were frozen at $-80^{\circ} \mathrm{C}$ and then thawed to lyse the cells, diluted $1: 1$ with autoclaved skim milk, and sonicated with a Fisher Sonic Dismembrator at power level 1 for $20 \mathrm{~s}$ to fully disrupt the cells and release virus particles. For measurement of culture medium yield, culture medium was withdrawn, cleared of suspended cells and debris by centrifugation at $14,000 \times g$ for $2 \mathrm{~min}$, and then diluted 1:1 with autoclaved milk to stabilize virus. The virus stocks were then subjected to titer determination on Vero cell monolayers, and the plaques were counted after being stained with amido black.

Measurement of virus binding to cells. Binding measurements were performed directly with the samples in glass scintillation vials at $4^{\circ} \mathrm{C}$ as previously described (18). Briefly, confluent monolayers of $\mathrm{BHK}\left(\mathrm{TK}^{-}\right)$or $95-19$ cells were pretreated for $1 \mathrm{~h}$ with PBS-1\% bovine serum albumin to block nonspecific virus adsorption. The cells were then inoculated with serial twofold dilutions of radiolabeled purified virions in PBS- $1 \%$ bovine serum albumin and placed on a shaker at $4^{\circ} \mathrm{C}$ for $5 \mathrm{~h}$. After the adsorption period, the viral inoculum was removed, the cells were washed three times in PBS, and cell-associated radioactivity was quantitated. Controls included uninfected cells and cells inoculated with virus in the presence of $100 \mu \mathrm{g}$ of soluble heparin per $\mathrm{ml}$ as a competitive inhibitor.

Plaque assays. Cultures of $\mathrm{BHK}\left(\mathrm{TK}^{-}\right)$or $95-19$ cells that were $50 \%$ confluent were exposed to virus at $37^{\circ} \mathrm{C}$ for $90 \mathrm{~min}$ and then incubated for $72 \mathrm{~h}$ in growth medium containing $0.01 \%$ pooled human immune globulin (Gammar; Armour Pharmaceutical) to permit virus plaque formation. The cultures were then washed with PBS and fixed in methanol at $-20^{\circ} \mathrm{C}$ for $20 \mathrm{~min}$. Virus plaques were detected by immunoassay with monoclonal antibody directed against HSV-1 glycoprotein D (Goodman Cancer Research Labs) as previously described (34). 

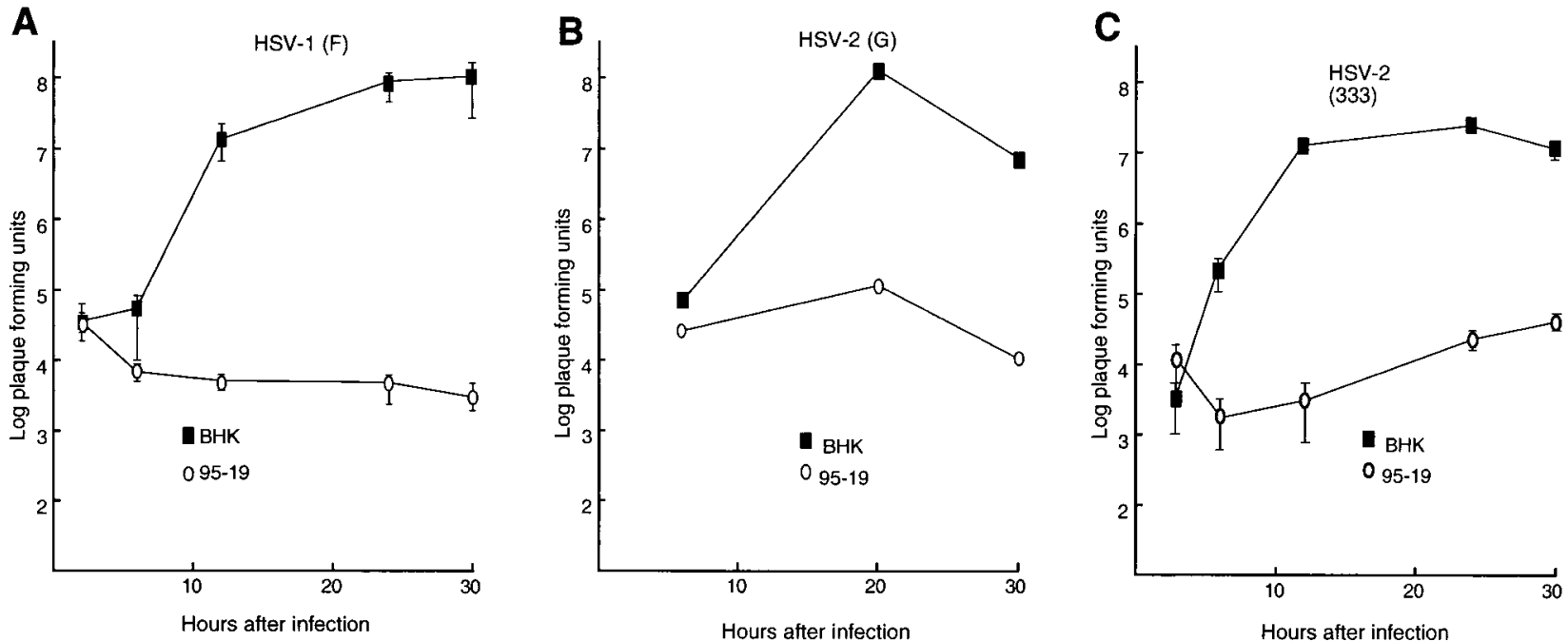

FIG. 1. Replication of HSV-1 and HSV-2 on BHK(TK $\left.{ }^{-}\right)$and $95-19$ cells. Shown are plots of the logarithm of PFU of virus accumulated in cultures of BHK(TK ${ }^{-}$) cells or 95-19 cells against time after infection. Cultures were infected, citrate treated, harvested, and subjected to titer determination on Vero cells as described in Materials and Methods. (A) HSV-1(F); (B) HSV-2(G); (C), HSV-2(333).

Isolation and analysis of RNA. Total RNA was isolated and analyzed by Northern blotting as previously described (34).

PEG fusion. Infected $25-\mathrm{cm}^{2}$ cultures were treated with $48 \%$ (wt/wt) PEG 8000 in PBS as previously described (34)

Quantification of $\boldsymbol{\beta}$-galactosidase expression from infected cells. $\mathrm{BHK}\left(\mathrm{TK}^{-}\right)$ or 95-19 cells in 96-well dishes $\left(\approx 5 \times 10^{4}\right.$ cells/well $)$ were exposed to HSV-1 (17)(dUTPase/LAT) at increasing multiplicities of infection at $37^{\circ} \mathrm{C}$. After a 5 -h period, the inoculum was removed and the cells were washed with PBS, fixed with glutaraldehyde, permeabilized with $0.1 \%$ Nonidet P-40 in PBS, and incubated with the soluble $\beta$-galactosidase substrate $o$-nitrophenyl- $\beta$-D-galactopyranoside (ONPG; $1 \mathrm{mg} / \mathrm{ml}$ in $0.1 \% \mathrm{NP}-40)$ for $1 \mathrm{~h}$ at $37^{\circ} \mathrm{C}$. The absorbance at 410 $\mathrm{nm}$ was then measured with a Dynatech MR600 microplate reader. Uninfected cells were included as controls.

Infectious-center assay. Duplicate cultures of $\mathrm{BHK}\left(\mathrm{TK}^{-}\right)$and $95-19$ cells in six-well plates $\left(10 \mathrm{~cm}^{2}\right)$ at $50 \%$ confluence were exposed to virus at various multiplicities of infection at $37^{\circ} \mathrm{C}$. The time of addition of virus was designated time zero of the infection. After $90 \mathrm{~min}$ of incubation to allow initiation of infection, the cells were washed once with PBS, once more rapidly with citrate buffer ( $50 \mathrm{mM}$ sodium citrate plus $4 \mathrm{mM} \mathrm{KCl}$, adjusted to $\mathrm{pH} 3.0$ with $\mathrm{HCl}$ ), and then incubated in a second wash of citrate buffer for 1 min to inactivate most of the residual virus. The monolayers were then washed twice in PBS to remove the low-pH buffer and placed in growth medium containing pooled human immunoglobulin to neutralize any extracellular virus. After $4 \mathrm{~h}$ of infection, one culture from each set of duplicates was treated with trypsin to detach the cells and half of the cell suspension was seeded into a six-well culture of Vero cells in growth medium containing $0.01 \%$ pooled human immune globulin (Gammar). All the cultures were then incubated at $37^{\circ} \mathrm{C}$ until $48 \mathrm{~h}$ after infection. They were then fixed, and plaques were visualized by immunostaining as previously described (34).

Vesicular stomatitis virus infection. Monolayers of Vero, $\mathrm{BHK}\left(\mathrm{TK}^{-}\right)$, and 95-19 cells were infected at 0.01 or 1 PFU/cell and incubated for 2 days in growth medium. The viral yield in the infected cultures was determined by scraping the cells into the culture medium, sonicating the cell suspension, and subjecting it to titer determination on Vero cells.

\section{RESULTS}

95-19 cells do not support efficient single-step growth of HSV-1 or HSV-2. It has been shown previously that the 95-19 cell line and a variety of other cell lines derived from BHK $\left(\mathrm{TK}^{-}\right)$cells are resistant to plaque formation by HSV-1(F) (34). Plaque formation is a relatively complex process, whose efficiency is determined by the efficiency of single-step growth and the efficiency of viral egress and cell-to-cell spread. To determine whether the 95-19 cells support efficient single-step growth, monolayer cultures of resistant 95-19 cells and susceptible $\mathrm{BHK}\left(\mathrm{TK}^{-}\right)$cells were infected with $\mathrm{HSV}$ at a multiplicity of infection of 10, washed with PBS and treated with $\mathrm{pH} 3.0$ buffer to remove and inactivate most of the residual virus, and incubated at $37^{\circ} \mathrm{C}$ to allow virus growth. At various times after infection, virus stocks were prepared from the infected cultures (cells and culture medium together) and the PFU count was determined by measurement of the titer on susceptible Vero cells (Fig. 1). Replication of HSV-1(F) on $\mathrm{BHK}\left(\mathrm{TK}^{-}\right)$cells showed typical kinetics with an increase in the PFU count of more than $3 \log$ orders of magnitude over that for the residual virus (i.e., the virus present at the earliest time point). On 95-19 cells, in contrast, HSV-1(F) showed no indication of replication. The viral titer in the infected cultures dropped continuously with time after infection, probably reflecting a loss of residual infecting virus. To determine whether the resistance to infection exhibited by $95-19$ cells was specific to HSV-1, we also determined the single-step growth yield and kinetics for two strains of HSV-2, strains G and 333 (Fig. 1B and $\mathrm{C}$ ). In no case did virus accumulate to levels significantly exceeding that of residual infecting virus, and in all cases, the yield of virus from the susceptible $\mathrm{BHK}\left(\mathrm{TK}^{-}\right)$cells exceeded that from the resistant cells by at least $2.5 \log$ orders of magnitude.

95-19 cells are resistant to virus entry. To determine at what stage single-step viral replication was blocked in 95-19 cells, we tested for expression of viral gene products of various kinetic classes, by measuring either accumulation of immediate-early (IE) mRNA or accumulation of a reporter gene product driven by a viral early-gene promoter from the viral genome. For measurement of IE mRNA, total RNA purified from BHK $\left(\mathrm{TK}^{-}\right)$and 95-19 cells infected with $10 \mathrm{PFU}$ of HSV-1(F) per cell for $4.5 \mathrm{~h}$ was separated on a formaldehyde-agarose gel, blotted to a nylon membrane, and probed with radiolabeled RNAs antisense to the ICP0, ICP27, and ICP22/47 mRNAs (Fig. 2A). No detectable expression of any immediate-early RNA was observed in the 95-19 cells even following extended exposure. Identical results were obtained with another strain of HSV-1 [HSV-1(17)(dUTPase/LAT)] and two strains of HSV-2 (G and 333).

Taking advantage of an HSV-1 strain, derived from HSV-1 (17), that contains the E. coli $\beta$-galactosidase gene under the control of the viral dUTPase gene promoter, we compared viral entry into $\mathrm{BHK}\left(\mathrm{TK}^{-}\right)$and $95-19$ cells. We have previously 

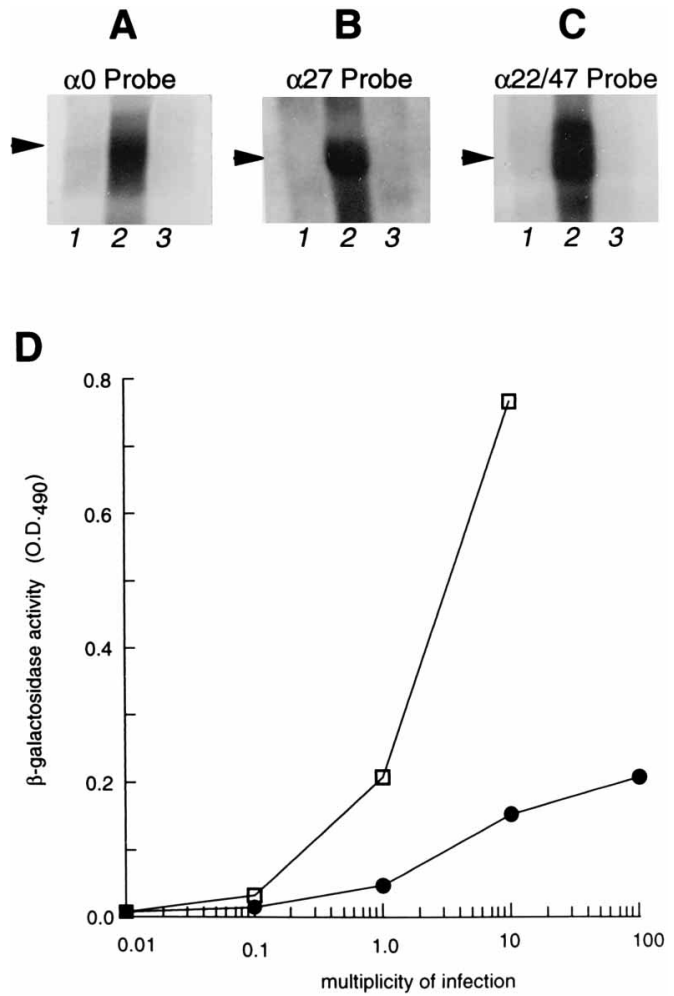

FIG. 2. Assay for HSV IE gene products in infected $\mathrm{BHK}\left(\mathrm{TK}^{-}\right)$and $95-19$ cells. (A) Autoradiographic image of a Northern (RNA) blot of formaldehydeagarose gel-separated RNAs purified from uninfected $\mathrm{BHK}\left(\mathrm{TK}^{-}\right)$cells (lane 1), BHK $\left(\mathrm{TK}^{-}\right)$cells infected with $10 \mathrm{PFU}$ of HSV-1(F) per cell for $5 \mathrm{~h}$ (lane 2), and 95-19 cells infected with $10 \mathrm{PFU}$ of HSV-1(F) per cell for $5 \mathrm{~h}$ (lane 3 ) and probed with labeled SP6 transcripts of pRB4352 to detect $\alpha 0$ mRNA. (B) Same as panel A but probed with SP6 transcripts of pRB4716 antisense to $\alpha 27$ mRNA. (C) Same as panel A but probed with SP6 transcripts of pRB3952 antisense to both $\alpha 22$ and $\alpha 47$ mRNAs. Arrows point to the migration position of the detected HSV RNAs. Both $\alpha 22$ and $\alpha 47$ mRNAs are detected in panel $\mathrm{C}$ but are not resolved on the gel. Equal amounts of total RNA were loaded in each lane. The autoradiograms are overexposed to show the lack of expression of IE mRNAs in the infected 95-19 cells. (D) Expression of $\beta$-galactosidase from HSV-1(17) (dUTPase/LAT) in BHK $\left(\mathrm{TK}^{-}\right)$and $95-19$ cells. A plot of $\beta$-galactosidase activity in infected cultures against multiplicity of infection is shown. The values for BHK $\left(\mathrm{TK}^{-}\right)$cells at a multiplicity of infection of 100 were highly inconsistent between experiments and are not shown. O.D.490, optical density at $490 \mathrm{~nm}$.

shown that the specific infectivity of HSV-1(17)(dUTPase/ LAT) is similar to that of HSV-1(17) (20a). Cells were exposed to HSV-1(17)(dUTPase/LAT) virus at various multiplicities of infection, and then cultures were assayed for $\beta$-galactosidase activity $5 \mathrm{~h}$ after infection as described in Materials and Methods (Fig. 2B). 95-19 cells showed much less accumulation of $\beta$-galactosidase activity than did $\mathrm{BHK}\left(\mathrm{TK}^{-}\right)$cells in response to increasing virus input, again demonstrating that 95-19 cells are highly resistant to infection and that the block occurs very early in infection.

Failure to detect IE gene expression showed that infection must be blocked at some stage prior to IE transcription and suggested that the virus might fail to enter the 95-19 cells. Efficient entry of HSV requires initial attachment to cell surface proteoglycan, other undefined virus-cell interactions, and subsequent fusion of the virus and cell membranes. To determine whether 95-19 cells support attachment to cell surface heparan sulfate, cultures of $\mathrm{BHK}\left(\mathrm{TK}^{-}\right)$and 95-19 cells were exposed to increasing amounts of purified, radiolabeled virus particles at $4^{\circ} \mathrm{C}$ in the presence or absence of competing soluble heparin, and after incubation and washing, cell-associated radioactivity was determined by scintillation counting (Fig. 3). Radiolabeled virus bound to $95-19$ cells and to $\mathrm{BHK}\left(\mathrm{TK}^{-}\right)$ cells equally well, and in both cases virus binding could be inhibited by the addition of soluble heparin. This result suggested that the block to single-step replication in 95-19 cells is manifested after attachment to cell surface proteoglycan but before IE gene transcription.

If the block to infection of 95-19 cells occurred at or before fusion of the virus and cellular membranes, we reasoned that it should be possible to overcome the block by forcing that fusion event by exposing cells and attached virus to the fusogen PEG. Furthermore, if resistance in 95-19 cells is simple and the block to entry is the only block to a single cycle of virus replication, PEG stimulation of entry and of virus yield should be quantitatively similar. To test this hypothesis, we treated cells and attached virus with PEG and then measured the efficiency of entry (reflected by immediate-early mRNA accumulation) and
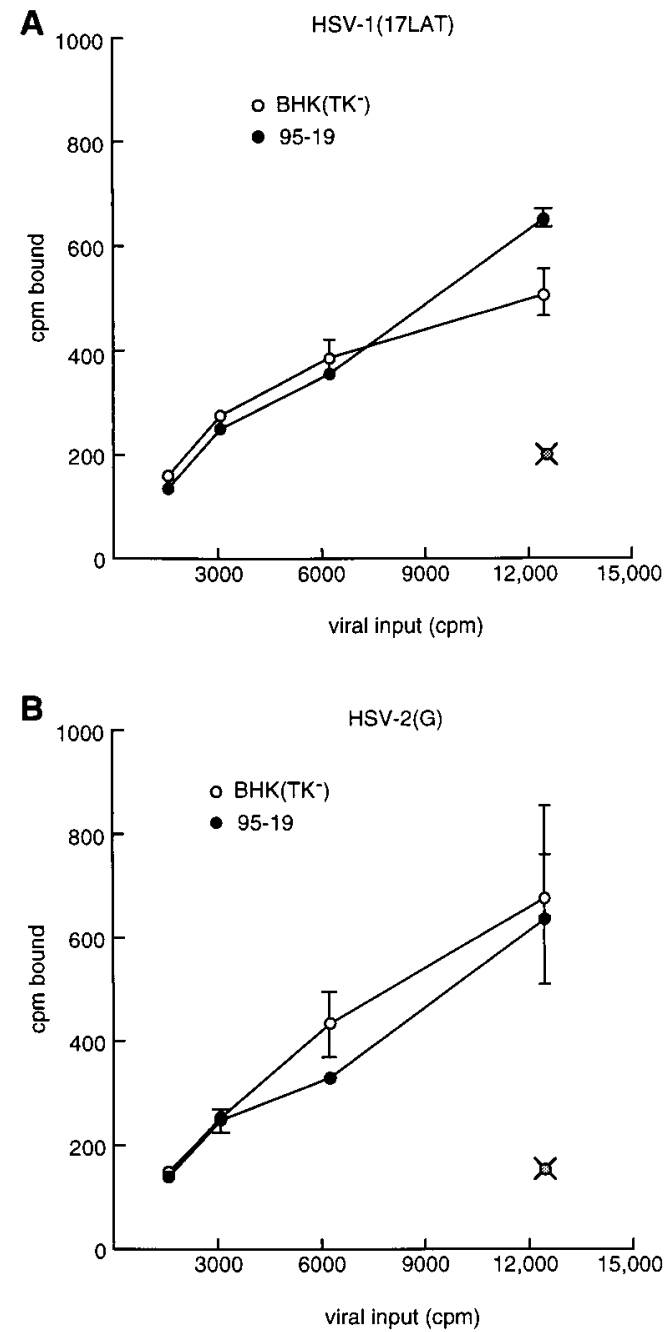

FIG. 3. Assay for heparin-sensitive attachment of $\mathrm{HSV}$ to $\mathrm{BHK}\left(\mathrm{TK}^{-}\right)$and 95-19 cells. Shown are plots of the amounts of labeled virus bound to BHK(TK $\left.{ }^{-}\right)$ cells and 95-19 cells against the amount of labeled virus input. The purified, radiolabeled virus preparations were subjected to titer determination, and in each panel the highest viral input $(12,500 \mathrm{cpm})$ corresponds to about $50 \mathrm{PFU} /$ cell. (A) Binding of HSV-1(17)(dUTPase/LAT). The position of the crossed, shaded circle shows the level of binding to 95-19 cells in the presence of $100 \mu \mathrm{g}$ of soluble heparin per ml. (B) Same as panel A, except that the input virus is HSV-2(G). 
the efficiency of replication (reflected by the total culture yield at $30 \mathrm{~h}$ postinfection). Cultures of $\mathrm{BHK}\left(\mathrm{TK}^{-}\right)$and 95-19 cells were exposed to $10 \mathrm{PFU}$ of virus per cell for $90 \mathrm{~min}$ at $4^{\circ} \mathrm{C}$ to permit attachment of virus to cells, but not entry. The cultures were then washed with warm medium to remove free virus and initiate infection, and some were exposed to PEG as described in Materials and Methods. After $1 \mathrm{~h}$ of incubation at $37^{\circ} \mathrm{C}$, the cultures were treated with citrate buffer $(\mathrm{pH} 3.0)$ to inactivate most of the residual virus. To assess PEG-mediated entry, at $5 \mathrm{~h}$ after the PEG treatment, RNA was isolated from some PEG-treated and untreated cultures, separated on a formaldehyde agarose gel, transferred to a Zeta-Probe membrane and probed with labeled SP6 transcripts of sequences from the $\alpha 0$ gene. $\alpha 0$ mRNA signals were quantitated with a Packard InstantImager. To assess PEG-mediated recovery of virus replication, virus stocks were prepared from some PEG-treated and untreated cultures at $30 \mathrm{~h}$ after initiation of infection and the viral yield in the cultures was determined by measurement of the titer of culture freeze-thaw lysates on Vero cells. A representative autoradiogram showing PEG stimulation of $\alpha 0$ mRNA accumulation is shown in Fig. 4A. In this experiment, PEG treatment induced a recovery of entry (as measured by IE mRNA expression) to about $15 \%$ of that seen in permissive $\mathrm{BHK}\left(\mathrm{TK}^{-}\right)$cells. The results of representative experiments showing PEG-mediated recovery of viral yield are shown in Fig. 4B. For HSV-1(F) in the absence of PEG, virus yield was depressed more than 4 log orders of magnitude and the yield at $30 \mathrm{~h}$ postinfection did not exceed the amount of residual infectivity in the cultures at $2 \mathrm{~h}$ postinfection. PEG treatment of cells and attached virus increased the yield of virus by more than $3 \log$ orders of magnitude and brought the efficiency of virus replication to just less than $10 \%$ of that seen on the permissive $\mathrm{BHK}\left(\mathrm{TK}^{-}\right)$cells. This experiment was repeated with a recombinant virus based on HSV-1(17), with two strains of HSV-2. Representative experiments are shown in Fig. 4B. In all cases, PEG treatment of cells and attached virus increased the yield of virus by at least 10 -fold, and the PEG-stimulated yield of all of the viruses on resistant cells (the 95-19 filled bars) was similar. In the experiments shown, the amount of virus in resistant, untreated cultures (the 95-19 open bars) was substantially larger for HSV-1(17), HSV-2(G), and HSV-2 (333) than for HSV-1(F), probably due to a less efficient inactivation of residual infectivity. These results suggest that the block to infection in 95-19 cells can be partially overcome by the action of a fusogen and that the block is therefore exerted prior to the fusion of viral and cellular membranes.

The quantitative results of several experiments in which IE mRNA expression and 30-h virus yield were measured in parallel for each of four strains of HSV-1 and HSV-2 are shwn in Table 1. For each virus, there is excellent correspondence between PEG-mediated recovery of virus entry (as assessed by ICP0 mRNA expression), and PEG-mediated recovery of single-step virus replication measured as the total culture yield of virus. These data demonstrate that there is no significant block to virus replication in 95-19 cells between the expression of IE mRNAs and the production of a normal yield of infectious virions. The assay for IE mRNA expression is a surrogate assay for entry; there are multiple steps between membrane fusion and IE mRNA transcription. It is unlikely that one of these steps is substantially blocked in $95-19$ cells, since the recovery of both entry and replication (5 to 10\%) that we see with PEG treatment is comparable to that obtained with susceptible cells and anti-gD-neutralized virus $(8 \%)(14)$ or susceptible cells infected with viral mutants defective in entry due to deletion of the $\mathrm{gB}$ gene $(0.2 \%)(5)$ or the $\mathrm{gD}$ gene $(0.5 \%)(26)$. In these cases, the only block to infection occurs at entry, and these

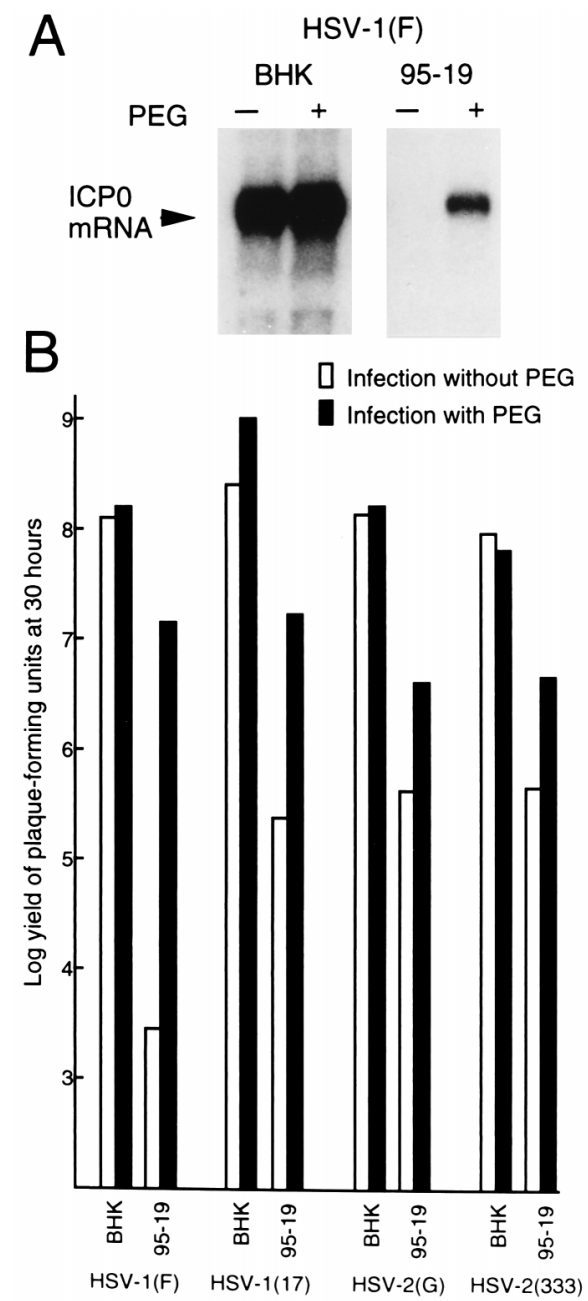

FIG. 4. Stimulation of HSV infection of 95-19 cells by PEG. (A) Autoradiographic image of a northern (RNA) blot of formaldehyde-agarose gel-separated RNAs purified from $\mathrm{BHK}\left(\mathrm{TK}^{-}\right)$cells or 95-19 cells infected, without or with PEG treatment, with 10 PFU of HSV-1(F) per cell for $5 \mathrm{~h}$, probed with labeled SP6 transcripts of pRB4352 to detect $\alpha 0$ mRNA. The BHK $\left(\mathrm{TK}^{-}\right)$lanes and the 95-19 lanes are from the same exposure of the same blot but were not adjacent on the blot. (B) Bar graph of the yield of virus (measured by titer determination of the culture lysate on Vero cells) at $30 \mathrm{~h}$ after infection of BHK and 95-19 cells with 10 PFU of the indicated viruses per cell without or with PEG treatment. Representative experiments are shown. Quantitation of multiple experiments is presented in Table 1 .

experiments thus provide a benchmark for estimating the efficiency of PEG-induced entry. It therefore seems highly likely that the surrogate assay accurately reflects entry of the virus and that the block to entry is the only quantitatively significant block to viral replication. For HSV-1(F), virus yield in the culture medium at $30 \mathrm{~h}$ was also determined by titer determination in the culture medium cleared of cells and debris by centrifugation, and these data are presented in Table 1. Release of free HSV-1(F) into the medium following replication in 95-19 cells is not stimulated by PEG treatment to the same degree as is the total virus yield, suggesting that the defect in 95-19 cells also affects viral egress or release from the surface of the cell into the medium.

95-19 cells are resistant to virus entry by cell-to-cell spread. The 95-19 cell line was originally isolated on the basis of its resistance to plaque formation by HSV. The results shown above suggested that the resistance to plaque formation is due, 
TABLE 1. Efficiencies of PEG-induced entry and replication in 95-19 cells

\begin{tabular}{lccc}
\hline \multicolumn{1}{c}{$\begin{array}{c}\text { Infecting } \\
\text { virus }\end{array}$} & $\begin{array}{c}\text { Entry } \\
\text { efficiency }^{a}\end{array}$ & $\begin{array}{c}\text { Culture yield } \\
\text { efficiency }^{b}\end{array}$ & $\begin{array}{c}\text { Medium yield } \\
\text { efficiency }^{c}\end{array}$ \\
\hline HSV-1(F) & $6.7 \%(3.7-9.5)$ & $14.3 \%(3.2-30.2)$ & $1.7 \%(0.6-3.8)$ \\
HSV-1(17) & $5.9 \%(4.5-7.0)$ & $5.1 \%(0.5-10.0)$ & ND $^{d}$ \\
$\quad$ dUTPase/LAT) & $10.1 \%(5.1-15.0)$ & $6.0 \%(4.0-7.5)$ & ND \\
HSV-2(G) & $4.0 \%$ & $7.5 \%$ & ND \\
HSV-2(333) & & & \\
\hline
\end{tabular}

${ }^{a}$ Efficiency of entry was measured in terms of ICP0 mRNA expression at $5 \mathrm{~h}$ postinfection. The efficiency is calculated as ICP0 mRNA cpm in 95-19 cells divided by ICP0 mRNA cpm in BHK(TK $\left.{ }^{-}\right)$cells and multiplied by 100 . ICP0 mRNA was not detectable in 95-19 cells infected but not treated with PEG. Numbers in parentheses indicate the range of values observed. Values for HSV-1 (F) are from three independent experiments. Those from HSV-1(17) and HSV-2 (G) are from two independent experiments. The values for HSV-2(333) represent a single experiment.

${ }^{b}$ Total culture yield was measured as virus PFU in the culture (medium and cells) at $30 \mathrm{~h}$ after infection with $10 \mathrm{PFU}$ of the indicated virus per cell. The yield efficiency is the value for PEG-treated 95-19 cells divided by the value for PEG-treated $\mathrm{BHK}\left(\mathrm{TK}^{-}\right)$cells and multiplied by 100.

${ }^{c}$ Medium yield was measured as virus PFU in medium cleared by centrifugation at $14,000 \times g$ for $2 \mathrm{~min}$ at $30 \mathrm{~h}$ after infection. The yield efficiency is the value for PEG-treated 95-19 cells divided by the value for PEG-treated $\mathrm{BHK}\left(\mathrm{TK}^{-}\right)$ cells and multiplied by 100 .

${ }^{d} \mathrm{ND}$, not determined.

at least in part, to resistance to initial entry of free virus into the cells. Although this is the only block to single-step replication in 95-19 cells, a further block to plaque formation might result if 95-19 cells also fail to support efficient egress of the virus from the initial host cell or entry of virus into subsequent host cells by cell-to-cell spread. We observed that infection of 95-19 cells at a high multiplicity of infection with a virus carrying a $\beta$-galactosidase reporter resulted in the detection of reporter activity in a small minority of cells shortly after exposure to the virus. The number of cells so infected greatly exceeded the number of plaques obtained after several days from an equivalent virus input (data not shown), suggesting that there is indeed a block to plaque formation acting after initial entry and successful replication of the virus.

Infectious-center assays were performed to test the hypothesis that 95-19 cells are resistant to infection by cell-to-cell spread. Duplicate monolayer six-well cultures $\left(10 \mathrm{~cm}^{2}\right)$ of BHK $\left(\mathrm{TK}^{-}\right)$and $95-19$ cells at $50 \%$ of confluence were exposed to various amounts of virus for $90 \mathrm{~min}$ at $37^{\circ} \mathrm{C}$ to allow entry and initiation of infection. The cells were then washed once with PBS and treated with low-pH citrate buffer to inactivate residual virus. Infection was then allowed to proceed at $37^{\circ} \mathrm{C}$ in growth medium containing $0.1 \%$ pooled human immune globulin, a source of neutralizing anti-HSV antibodies. At $4 \mathrm{~h}$ after infection, one culture from each set of duplicates was trypsinized to detach the cells, half of each cell suspension was seeded into a monolayer of Vero cells, and these cultures were incubated in medium containing human immune globulin to prevent infection by free virus. At $48 \mathrm{~h}$ after infection, all of the cultures were fixed and immunostained to allow visualization of plaques. Plaques developing on the Vero cells indicated the presence of infectious centers [i.e. $\mathrm{BHK}\left(\mathrm{TK}^{-}\right)$or $95-19$ cells that had become infected and supported virus replication and egress to a degree that permitted infection of an adjacent susceptible cell by cell-to-cell spread]. We reasoned that if the cells tested are fully susceptible to infection by cell-to-cell spread, there should be no difference between the number of infectious centers evident on Vero cells and the number of plaques on the test cells themselves. If the cells tested are resistant to infection by cell-to-cell spread, the number of infectious cen- ters should exceed the number of plaques formed on the test cells themselves. The results of the infectious-center assays are shown in Table 2. For BHK $\left(\mathrm{TK}^{-}\right)$cells, the number of infectious centers and the number of $\mathrm{BHK}\left(\mathrm{TK}^{-}\right)$plaques were the same, suggesting that, as expected, these cells show no significant block to entry by cell-to-cell spread. For 95-19 cells, the number of infectious centers greatly exceeded the number of 95-19 plaques formed at all multiplicities of infection tested, suggesting that these cells are indeed resistant to infection by cell-to-cell spread.

95-19 cells are resistant to escape mutants of HSV-1 that grow on other cell lines resistant to entry and to PRV. Other cell lines resistant to virus entry have been used for the isolation of escape mutants that can grow more efficiently than wild-type virus on the resistant cells. Several groups have reported the properties of viruses carrying mutations in the gene encoding gD that grow more efficiently than the wild-type virus on cells that express $\mathrm{gD}$ or on a cell line that expresses the HSV-1 $\mathrm{U}_{\mathrm{s}} 11$ gene product $(2,7,8,34)$. If the mechanism of resistance to infection shown by $95-19$ cells is essentially the same as that seen in these other resistant cell types, these mutant viruses should show a similarly enhanced ability to infect 95-19 cells. We determined the efficiency with which a variety of such mutants replicated on 95-19 cells by measuring viral yield at $30 \mathrm{~h}$ after infection. Monolayer cultures of susceptible $\mathrm{BHK}\left(\mathrm{TK}^{-}\right)$cells and resistant 95-19 cells were infected with test viruses at a multiplicity of infection of 5, treated with low-pH buffer to remove most residual virus, and then incubated at $37^{\circ} \mathrm{C}$ to permit the growth of virus. Stocks were prepared from infected cultures at $5 \mathrm{~h}$ after infection (for determination of residual infecting virus) and at $30 \mathrm{~h}$ after infection and subjected to titer determination on Vero cells (Fig. 5). The R5000 mutant described by Roller and Roizman was shown to be able to infect $\mathrm{U}_{\mathrm{s}} 11$-expressing cells and $\mathrm{gD}$ expressing BJ cell line several log orders of magnitude more efficiently than the wild-type HSV-1(F) was (34). We observed that this virus grew no more efficiently than wild-type HSV-1 (F) on 95-19 cells. Similarly, the rid1 and rid2 mutants derived from HSV-1(KOS) isolated by Dean et al. (8), which form plaques on HSV-1 gD-expressing HEp-2 cells several thousandfold more efficiently than does wild-type virus and that show enhanced infectivity on CHO-K1 cells, did not grow significantly better than HSV-1(KOS) on 95-19 cells. The U21 mutant described by Brandimarti et al. (2), whose growth was found to be enhanced on resistant, gD-expressing BJ cells,

TABLE 2. Formation of infectious centers and plaques on susceptible $\mathrm{BHK}\left(\mathrm{TK}^{-}\right)$and resistant $95-19$ cells

\begin{tabular}{|c|c|c|c|}
\hline Test cells & Input $\mathrm{PFU}^{a}$ & $\begin{array}{l}\text { No. of infectious } \\
\text { centers }^{b}\end{array}$ & $\begin{array}{l}\text { Test cell } \\
\text { plaques }^{c}\end{array}$ \\
\hline $\mathrm{BHK}\left(\mathrm{TK}^{-}\right)$ & $\begin{array}{l}5 \times 10^{4} \\
5 \times 10^{3} \\
5 \times 10^{2}\end{array}$ & $\begin{array}{c}\text { TNTC }^{d} \\
305 \pm 63 \\
26 \pm 8\end{array}$ & $\begin{array}{c}\text { TNTC } \\
277 \pm 56 \\
27 \pm 9\end{array}$ \\
\hline $95-19$ & $\begin{array}{l}5 \times 10^{8} \\
5 \times 10^{7} \\
5 \times 10^{6}\end{array}$ & $\begin{array}{c}\text { TNTC } \\
379 \pm 38 \\
36 \pm 30\end{array}$ & $\begin{array}{c}3 \pm 2 \\
0 \\
0\end{array}$ \\
\hline
\end{tabular}

${ }^{a}$ Determined by determination of the titer of virus stock on Vero cells.

${ }^{b}$ The number of plaques obtained following seeding of infected test cells onto a Vero cell monolayer in the presence of neutralizing antibody. Numbers represent the mean of three independent experiments plus or minus the sample standard deviation.

${ }^{c}$ Number of plaques observed on the infected test cell monolayer. Plaques are defined as two or more adjacent infected cells. Macroscopic plaques were rarely formed on 95-19 cells. Numbers represent the mean of three independent experiments plus or minus the sample standard deviation.

${ }^{d}$ TNTC, too numerous to count. 


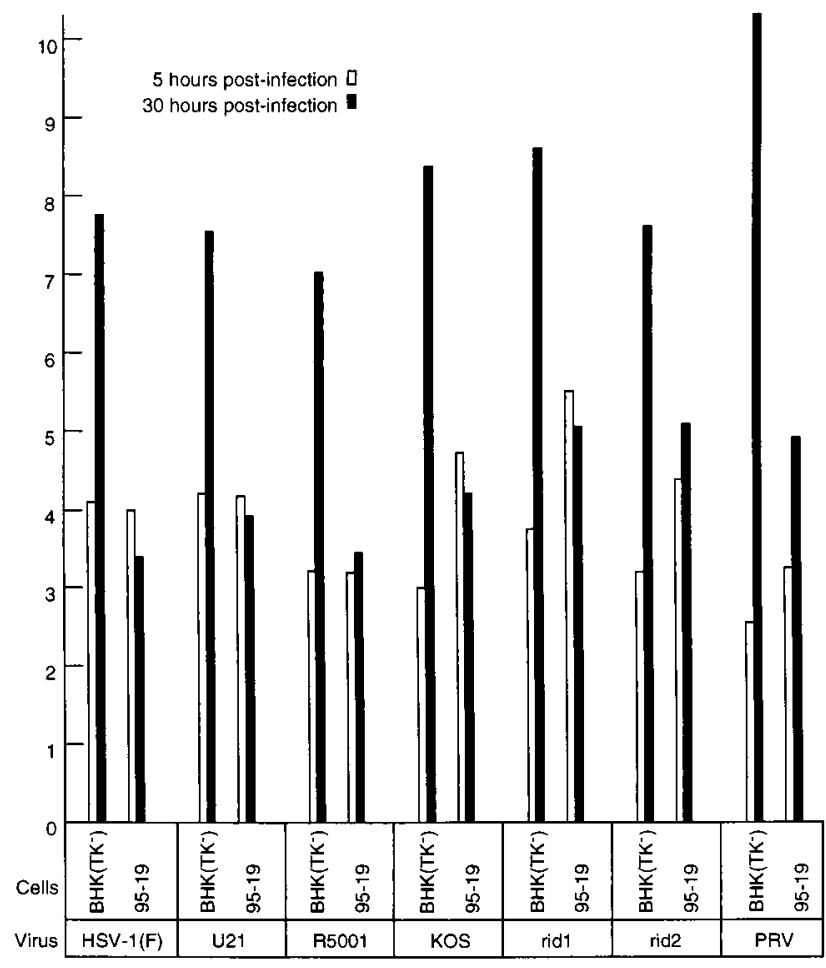

FIG. 5. Growth of HSV-1 mutants and PRV on BHK(TK $\left.{ }^{-}\right)$and 95-19 cells. The logarithm of culture yields (determined by titer determination on Vero cells) at $5 \mathrm{~h}$ and $30 \mathrm{~h}$ after infection with $5 \mathrm{PFU}$ of the indicated virus per cell is shown.

$\mathrm{U}_{\mathrm{s}}$ 11-expressing cells, and normal $\mathrm{BHK}\left(\mathrm{TK}^{-}\right)$cells, also showed no evidence of growth on 95-19 cells. Wild-type PRV also failed to grow efficiently on 95-19 cells. The resistance to PRV was not as complete as that seen for HSV, in that we consistently observed low-level growth on the resistant cells and PRV formed substantial-sized plaques on 95-19 cells (results not shown). The high-level resistance of 95-19 cells to PRV distinguishes these cells clearly from HSV-resistant cells that are fully susceptible to PRV, such as ST cells $(41,42)$ and $\mathrm{U}_{\mathrm{s}} 11 \mathrm{cl} 19$ cells (32).

Specificity of 95-19 resistance to infection. The resistance shown by 95-19 cells to HSV infection might reflect either a specific resistance to herpesvirus infection due to failure to support an interaction essential for HSV entry or a more global defect in membrane function, so that infection by any enveloped virus might be inhibited. To determine whether the block to infection is specific, we determined whether 95-19 cells were resistant to a member of another enveloped virus family, VSV. The entry of VSV occurs by endocytosis followed by a low-pH-catalyzed fusion of the virus envelope with the endosomal membrane (28). Cultures of $\mathrm{BHK}\left(\mathrm{TK}^{-}\right)$, 95-19, and Vero cells were exposed to $0.01 \mathrm{PFU}$ of VSV (Indiana) per cell, and viral stocks were prepared from cultures at $30 \mathrm{~h}$ after infection and then subjected to titer determination on Vero cells (Table 3). VSV replicated with similar efficiencies on Vero and 95-19 cells $\left(1.0 \times 10^{6}\right.$ and $9.3 \times 10^{5} \mathrm{PFU}$, respectively). Surprisingly, the growth of VSV on $\mathrm{BHK}\left(\mathrm{TK}^{-}\right)$cells $\left(1.9 \times 10^{4}\right.$ PFU) was substantially less efficient than on 95-19 cells. The basis for this difference is unclear. These results suggest that 95-19 cells are susceptible to the entry of non-HSV enveloped virus and that the block to HSV infection is specific.

\section{DISCUSSION}

We have observed that 95-19 cells demonstrate high-level resistance to infection by a variety of strains of both HSV-1 and HSV-2 and by PRV. The resistance to infection exhibited by 95-19 cells is stable over many months and passages (data not shown), suggesting that resistance is a heritable property of the cells in the line and that the resistant line arose as a result of a mutation in the genome of one of the cells of the susceptible $\mathrm{BHK}\left(\mathrm{TK}^{-}\right)$parent line. Brandimarti et al. have shown that the $\mathrm{BHK}\left(\mathrm{TK}^{-}\right)$cell line, although susceptible to infection, is not as susceptible as Vero cells (2), and our own observations suggest that this line contains a mixture of susceptible and resistant cells.

This resistance to infection is manifested at a step after the binding of virus to cell surface proteoglycan, inasmuch as heparin-inhibitable binding of virus to both resistant and susceptible cells is equivalent. The resistance to infection is exerted at or before fusion of the viral and cellular membranes, since treatment of cells and attached virus by the fusogenic agent PEG is capable of overcoming it to an extent. The correspondence between PEG-induced recovery of IE mRNA expression and single-step virus yield strongly suggests that 95-19 cells exert only a single block to single-step replication that is manifested at a step in entry following attachment to cell surface proteoglycan and before fusion of the viral and cellular membranes.

95-19 cells were originally identified as resistant to infection because of their failure to support efficient plaque formation. Efficiency of plaque formation is affected not only by the efficiency of single-step replication but also by the efficiency of virus egress and cell-to-cell spread. In addition to resistance to the entry of free virus, our data suggest that resistance to plaque formation in $95-19$ cells is due to interference with these latter two processes.

Entry of alphaherpesviruses from the extracellular medium and entry of the virus by cell-to-cell spread between adjacent cells apparently do not occur by identical pathways. Specifically, studies on both PRV and HSV show that the viral genetic requirements for the two types of entry differ. It is not yet known whether the cellular factors required for cell-to-cell spread are different from those required for the entry of free virus, but it seems likely that the differences in viral requirements for the two types of entry are a reflection of different interactions with the surface of the host cell. Two observations show that the 95-19 cells are resistant to infection by cell-tocell spread, suggesting that they are deficient in some factor required for entry by both pathways. First, for HSV-1(17), the efficiency of entry of free virus exceeds the efficiency of plaque formation. Since the block to the entry of free virus is the only significant block to single-step replication, this result suggests that there is a further block to cell-to-cell spread. Second, infectious-center assays (Fig. 5) demonstrate that although some 95-19 cells become infected at high multiplicity and support viral replication and egress efficiently enough to permit cell-to-cell spread to susceptible cells, the vast majority cannot nucleate plaque formation when surrounded by other 95-19 cells.

95-19 cells show an impairment in their ability to support three steps in plaque formation. They show severe blocks to the entry of free virus and to the entry of virus by cell-to-cell spread and a lower-level block to egress or release of HSV-1. While it is possible that these distinct blocks represent three independent defects in the 95-19 cells, a more economical hypothesis is that the three processes interfered with use a common cellular factor that is deficient in this cell line. 
The events of herpesvirus entry that fall between attachment of cell surface proteoglycan and fusion of the viral and cellular membranes are not thoroughly characterized. It is thought that at this time the virus makes at least one interaction with a cell surface factor mediated by the virion glycoprotein D. This interaction can be blocked by UV-inactivated virus particles and by soluble $\mathrm{gD}$ and probably by cellular expression of $\mathrm{gD}(2$, $8,21-23,26)$. Other cell lines resistant to HSV infection that are thought to interfere with this gD-mediated step of entry have been reported. Cell lines that express the virion glycoprotein $\mathrm{D}$ are thought to interfere with infection by way of sequestration of a gD-binding cell surface factor by the endogenously expressed $\mathrm{gD}(2,8,22)$. The virus escape mutants whose mutations map to the $\mathrm{gD}$ gene may overcome this resistance by allowing the mutant $\mathrm{gD}$ to use an alternative binding interaction for entry $(2,8)$. It is not clear whether the deficiency in 95-19 cells also affects the interaction between $\mathrm{gD}$ and its cell surface receptor. We have observed that virus escape mutants that effect entry into gD-expressing cells and the $\mathrm{U}_{\mathrm{s}} 11 \mathrm{cl} 19$ cell line fail to allow efficient growth in $95-19$ cells. This outcome is consistent with two hypotheses. (i) The 95-19 cells are deficient both in the normal cellular factor required for the gD-host cell interaction and in the alternate receptors used by the $\mathrm{gD}$ interference escape mutants. (ii) HSV-1 makes an essential interaction in addition to that between $\mathrm{gD}$ and its receptor, and the 95-19 cells are deficient in a cellular factor that mediates this additional interaction. There is as yet little evidence that any viral glycoprotein other than $\mathrm{gD}$ makes an essential, postattachment binding interaction with the cell surface prior to entry, but $\mathrm{gB}$ and $\mathrm{gH}$ play some essential role both in postattachment entry of free virus and in cell-to-cell spread. The viral $\mathrm{gB}$, in addition to interacting with heparan sulfate at attachment, has been shown to be essential for postattachment entry and might make subsequent interactions that are blocked in 95-19 cells. With regard to gH and gL, Lee and Fuller (25) and Forrester et al. (11) have observed that whereas wild-type HSV-1 virions can block challenge by superinfecting virions on Vero cells, virions lacking $\mathrm{gH}$ are impaired in their ability to do so. The impaired ability of $\mathrm{gH}^{-}$virions to block infection is analogous to that obtained with $\mathrm{gD}^{-}$virus (although quantitatively much less dramatic) and may suggest that $\mathrm{gH}$ or $\mathrm{gL}$ also makes a functional interaction with some cellular factor.

The 95-19 cells show a spectrum of properties quite different from those of other cell lines that are reported to be resistant to postattachment entry of herpesviruses and that do not express gD. They exhibit high-level resistance to multiple strains of HSV-1 and HSV-2, suggesting that they fail to support an interaction required for efficient entry of all HSV strains. In this regard, they are distinguishable from the $\mathrm{CHO}$ cells described by Shieh et al., which are quite susceptible to some strains of HSV-2 (38). 95-19 cells are also distinguished by their resistance to PRV from ST cells and from $\mathrm{U}_{\mathrm{s}}$ 11-expressing cells, both of which are completely susceptible to this virus $(41,42)$. The existence of a single, simple, stable block to infection allows these cells to be used as a tool for isolating virus escape mutants in order to identify the viral gene products whose function is interfered with and, possibly, for the identification of cellular susceptibility-conferring genes in the confidence that one knows that virus entry is the only process affected.

\section{ACKNOWLEDGMENTS}

We are grateful to Ed Wagner, Pat Spear, and Gabriella Campadelli-Fiume for providing viral strains. We thank Brian Belval, Alicia Siston, Josh Herbeck, and John Ferguson for technical support.

This work was supported by the University of Iowa, by Research
Project grant RPG-97-070-01-VM from The American Cancer Society, by a Public Health Service grant from the National Institute for Allergy and Infectious Diseases (AI36318), and a Young Investigator Award from the IDSA/Burroughs Wellcome (to B.C.H.)

\section{REFERENCES}

1. Balan, P., N. Davis-Poynter, S. Bell, H. Atkinson, H. Browne, and T. Minson. 1994. An analysis of the in vitro and in vivo phenotypes of mutants of herpes simplex virus type 1 lacking glycoproteins $\mathrm{gG}$, gE, gI or the putative gJ. J. Gen. Virol. 75:1245-1258.

2. Brandimarti, R., T. Huang, B. Roizman, and G. Campadelli-Fiume. 1994. Mapping of herpes simplex virus 1 genes with mutations which overcome host restrictions to infection. Proc. Natl. Acad. Sci. USA 91:5406-5410.

3. Brunetti, C. R., R. L. Burke, B. Hoflack, T. Ludwig, K. S. Dingwell, and D. C. Johnson. 1995. Role of mannose-6-phosphate receptors in herpes simplex virus entry into cells and cell-to-cell transmission. J. Virol. 69:3517-3528.

4. Brunetti, C. R., R. L. Burke, S. Kornfeld, W. Gregory, F. R. Masiarz, K. S. Dingwell, and D. C. Johnson. 1994. Herpes simplex virus glycoprotein D acquires mannose 6-phosphate residues and binds to mannose 6-phosphate receptors. J. Biol. Chem. 269:17067-17074.

5. Cai, W., B. Gu, and S. Person. 1988. Role of glycoprotein B of herpes simplex virus type 1 in viral entry and cell fusion. J. Virol. 62:2596-2604.

6. Campadelli-Fiume, G., M. Arsenakis, F. Farabegoli, and B. Roizman. 1988 Entry of herpes simplex virus 1 in BJ cells that constitutively express viral glycoprotein D is by endocytosis and results in degradation of the virus. J. Virol. 62:159-167.

7. Campadelli-Fiume, G., S. Qi, E. Avitabile, L. Foa-Tomasi, R. Brandimarti, and B. Roizman. 1990. Glycoprotein D of herpes simplex virus encodes a domain which precludes penetration of cells expressing the glycoprotein by superinfecting herpes simplex virus. J. Virol. 64:6070-6079.

8. Dean, H. J., S. S. Terhune, M. T. Shieh, N. Susmarski, and P. G. Spear. 1994. Single amino acid substitutions in $\mathrm{gD}$ of herpes simplex virus 1 confer resistance to $\mathrm{gD}$-mediated interference and cause cell-type-dependent alterations in infectivity. Virology 199:67-80.

9. Dingwell, K. S., C. R. Brunetti, R. L. Hendricks, Q. Tang, M. Tang, A. J. Rainbow, and D. C. Johnson. 1994. Herpes simplex virus glycoproteins E and I facilitate cell-to-cell spread in vivo and across junctions of cultured cells. J. Virol. 68:834-845.

10. Dingwell, K. S., L. C. Doering, and D. C. Johnson. 1995. Glycoproteins E and I facilitate neuron-to-neuron spread of herpes simplex virus. J. Virol. 69: 7087-7098.

11. Forrester, A., H. Farrell, G. Wilkinson, J. Kaye, N. Davis-Poynter, and T. Minson. 1992. Construction and properties of a mutant herpes simplex virus type 1 with glycoprotein $\mathrm{H}$ coding sequences deleted. J. Virol. 66:341-348.

12. Fuller, A. O., and W.-C. Lee. 1992. Herpes simplex virus type 1 entry through a cascade of virus-cell interactions requires different roles of $\mathrm{gD}$ and $\mathrm{gH}$ in penetration. J. Virol. 66:5002-5012.

13. Fuller, A. O., R. Santos, and P. G. Spear. 1989. Potent neutralizing antibodies to $\mathrm{gH}$ of herpes simplex virus do not block attachment but prevent penetration of virus. J. Virol. 63:3535-3543.

14. Fuller, A. O., and P. G. Spear. 1987. Anti-glycoprotein D antibodies that permit adsorption but block infection by herpes simplex virus 1 preven virion-cell fusion at the cell surface. Proc. Natl. Acad. Sci. USA 84:54545458 .

15. Gruenheid, S., L. Gatzke, H. Meadows, and F. Tufaro. 1993. Herpes simplex virus infection and propagation in a mouse $\mathrm{L}$ cell mutant lacking heparan sulfate proteoglycans. J. Virol. 67:93-100.

16. Herold, B. C., S. I. Gerber, B. J. Belval, A. M. Siston, and N. Shulman. 1996. Differences in the susceptibility of herpes simplex virus types 1 and 2 to modified heparin compounds suggest serotype differences in viral entry. J. Virol. 70:3461-3469.

17. Herold, B. C., R. J. Visalli, N. Susmarski, C. R. Brandt, and P. G. Spear. 1994. Glycoprotein C-independent binding of herpes simplex virus to cells requires cell surface heparan sulfate and glycoprotein B. J. Gen. Virol. 75: 1211-1222.

18. Herold, B. C., D. WuDunn, N. Soltys, and P. G. Spear. 1991. Glycoprotein C of herpes simplex virus type 1 plays a principal role in adsorption of virus to cells and in infectivity. J. Virol. 65:1090-1098.

19. Highlander, S., S. L. Sutherland, P. J. Gage, D. C. Johnson, M. Levine, and J. C. Glorioso. 1987. Neutralizing monoclonal antibodies specific for herpes simplex virus glycoprotein D inhibit virus penetration. J. Virol. 61:33563364 .

20. Hutchinson, L., F. L. Graham, W. Cai, C. Debroy, S. Person, and D. C Johnson. 1993. Herpes simplex virus (HSV) glycoproteins B and K inhibit cell fusion induced by HSV syncytial mutants. Virology 196:514-531.

20a.Immergluck, L., M. Domowicz, N. Schwartz, and B. C. Herold. Submitted for publication.

21. Johnson, D. C., R. L. Burke, and T. Gregory. 1990. Soluble forms of herpes simplex virus glycoprotein D bind to a limited number of cell surface receptors and inhibit virus entry into cells. J. Virol. 64:2569-2576.

22. Johnson, D. C., and M. W. Ligas. 1988. Herpes simplex viruses lacking glycoprotein D are unable to inhibit virus penetration: quantitative evidence 
for virus specific cell surface receptors. J. Virol. 62:4605-4612.

23. Johnson, R. M., and P. G. Spear. 1989. Herpes simplex virus glycoprotein D mediates interference with herpes simplex virus infection. J. Virol. 63:819827.

24. Kritas, S. K., M. B. Pensaert, and T. C. Mettenleiter. 1994. Invasion and spread of single glycoprotein deleted mutants of Aujeszky's disease virus (ADV) in the trigeminal nervous pathway of pigs after intranasal inoculation. Vet. Microbiol. 40:323-334.

25. Lee, W. C., and A. O. Fuller. 1993. Herpes simplex virus type 1 and pseudorabies virus bind to a common saturable receptor on Vero cells that is not heparan sulfate. J. Virol. 67:5088-5097.

26. Ligas, M. W., and D. C. Johnson. 1988. A herpes simplex virus mutant in which glycoprotein D sequences are replaced by $\beta$-galactosidase sequences binds to but is unable to penetrate into cells. J. Virol. 62:1486-1494.

27. MacLean, C. A., S. Efstathiou, M. L. Elliott, F. E. Jamieson, and D. J. McGeoch. 1991. Investigation of herpes simplex virus type 1 genes encoding multiply inserted membrane proteins. J. Gen. Virol. 72:897-906.

28. Matlin, K. S., H. Reggio, A. Helenius, and K. Simons. 1982. Pathway of vesicular stomatitis virus entry leading to infection. J. Mol. Biol. 156:609631.

29. Montgomery, R. I., M. S. Warner, B. J. Lum, and P. G. Spear. 1996. Herpes simplex virus- 1 entry into cells mediated by a novel member of the TNF/ NGF receptor family. Cell 87:427-436.

30. Mulder, W. A., L. Jacobs, J. Priem, G. L. Kok, F. Wagenaar, T. G. Kimman, and J. M. Pol. 1994. Glycoprotein gE-negative pseudorabies virus has a reduced capability to infect second- and third-order neurons of the olfactory and trigeminal routes in the porcine central nervous system. J. Gen. Virol. 75:3095-3106

31. Peeters, B., N. de Wind, M. Hooisma, F. Wagenaar, A. Gielkens, and R. Moormann. 1992. Pseudorabies virus envelope glycoproteins gp50 and gII are essential for virus penetration, but only gII is involved in membrane fusion. J. Virol. 66:894-905.

32. Rauch, D., and R. Roller. Unpublished observations.

33. Rauh, I., and T. C. Mettenleiter. 1991. Pseudorabies virus glycoproteins gII and gp50 are essential for virus penetration. J. Virol. 65:5348-5356.
34. Roller, R., and B. Roizman. 1994. A herpes simplex virus-1 $\mathrm{U}_{\mathrm{s}} 11$-expressing cell line is resistant to herpes simplex virus infection at a step in viral entry mediated by glycoprotein D. J. Virol. 68:2830-2839.

35. Roop, C., L. Hutchinson, and D. C. Johnson. 1993. A mutant herpes simplex virus type 1 unable to express glycoprotein $\mathrm{L}$ cannot enter cells and its particles lack glycoprotein H. J. Virol. 67:2285-2297.

36. Sarmiento, M., M. Haffey, and P. G. Spear. 1979. Membrane proteins specified by herpes simplex viruses. III. Role of glycoprotein VP7 (B2) in virion infectivity. J. Virol. 29:1149-1158.

37. Sears, A. E., B. S. McGwire, and B. Roizman. 1991. Infection of polarized MDCK cells with herpes simplex virus 1 : two asymmetrically distributed cell receptors interact with different viral proteins. Proc. Natl. Acad. Sci. USA 88:5087-5091.

38. Shieh, M.-T., D. WuDunn, R. I. Montgomery, J. Esko, and P. G. Spear. 1992. Cell surface receptors for herpes simplex virus are heparin sulfate proteoglycans. J. Cell Biol. 116:1273-1281.

39. Shieh, M. T., and P. G. Spear. 1994. Herpesvirus-induced cell fusion that is dependent on cell surface heparan sulfate or soluble heparin. J. Virol. 68: 1224-1228.

40. Singh, J., and E. K. Wagner. 1995. Herpes simplex virus recombination vectors designed to allow insertion of modified promoters into transcriptionally "neutral" segments of the viral genome. Virus Genes 10:127-136.

41. Subramanian, G., R. A. LeBlanc, R. C. Wardley, and A. O. Fuller. 1995. Defective entry of herpes simplex virus types 1 and 2 into porcine cells and lack of infection in infant pigs indicate species tropism. J. Gen. Virol. 76: 2375-2379.

42. Subramanian, G., D. S. McClain, A. Perez, and A. O. Fuller. 1994. Swine testis cells contain functional heparan sulfate but are defective in entry of herpes simplex virus. J. Virol. 68:5667-5676.

43. Wittels, M., and P. G. Spear. 1990. Penetration of cells by herpes simplex virus does not require a low $\mathrm{pH}$-dependent endocytic pathway. Virus Res. 18:271-290.

44. WuDunn, D. W., and P. G. Spear. 1989. Initial interaction of herpes simplex virus with cells is binding to heparin sulfate. J. Virol. 63:52-58. 